\title{
Combination of LINE-1 hypomethylation and RASSF1A promoter hypermethylation in serum DNA is a non-invasion prognostic biomarker for early recurrence of hepatocellular carcinoma after curative resection
}

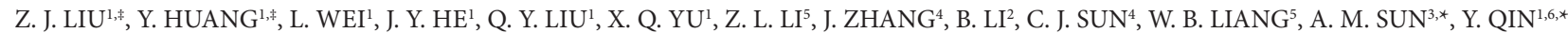

${ }^{1}$ Department of Biochemistry and Molecular Biology, West China School of Preclinical and Forensic Medicine, Sichuan University, Chengdu 610041, China; ${ }^{2}$ Division of Liver Transplantation, Department of Liver surgery, West China Hospital, Sichuan University, Chengdu, Sichuan Province, China; ${ }^{3}$ Analytical \& testing center, Sichuan University, Chengdu, Sichuan Province, China; ${ }^{4}$ West China School of Public Health, Sichuan University, Chengdu 610041, China; ${ }^{5}$ Department of Forensic Genetics, West China School of Basic Science and Forensic Medicine, Sichuan University, Chengdu 610041, China; ${ }^{6}$ Sichuan University "985 project-Science and technology innovation platform for novel drug development", Chengdu, 610041, China

*Correspondence: qin_1@sina.com, 2640842542@qq.com

${ }^{*}$ Contributed equally to this work.

Received October 21, 2016 / Accepted March 8, 2017

Hepatocarcinogenesis, a multistep process, involves not only genetic mutations but also epigenetic alterations. Widespread of global DNA hypomethylation is accompanied with specific regional hypermethylation especially at tumor suppressor genes' promoters. The aim of this study is to determine the efficacy of combined DNA methylation analysis of a global DNA methylation marker - LINE-1 and a tumor suppressor gene highly associated with the malignancy of HCC- RASSF1A in serum as a novel prognostic marker for diagnosis of early recurrence after curative resection.

LINE-1 was hypomethylated in 66.7\% (70/105) and RASSF1A promoter was hypermethylated in $73.3 \%(77 / 105)$ of HCC serum DNA samples by methylation specific PCR, but in none of the healthy controls: LINE-1 hypometylation (0/50) and RASSF1A hypermethylation (0/50). A significant association was found between LINE-1 hypomethylation and clinical pathologic features including HBsAg positivity $(\mathrm{p}=0.009)$, tumor size $(\mathrm{p}=0.001)$ and AFP levels $(\mathrm{p}<0.001)$. Besides, significant correlation was detected between RASSF1A promoter hypermethylation and lymph nodes metastasis $(\mathrm{p}=0.045)$.

The results of Kaplan-Meier estimates of survival suggested that LINE-1 hypomethylation was highly associated with poor survival of patients (disease-free survival $\mathrm{p}=0.002$, overall survival $\mathrm{p}=0.0123$ ). More importantly, co-evaluation of LINE- 1 hypomethylation and RASSF1A promoter hypermethylation was found to be significantly correlated to early recurrence and poor prognosis (disease-free survival $\mathrm{p}=0.0001$, overall survival $\mathrm{p}=0.05$ ) in patients after curative resection.

In conclusion, our study showed that the combined examination of LINE-1 hypomethylation and RASSF1A promoter hypermethylation was effective in predicting early recurrence of $\mathrm{HCC}$ after curative resection. Patients with dual positivity of LINE- 1 hypomethylation and RASSF1A promoter hypermethylation should be supplied with more intensive care and close follow-up after they undergo tumor resection.

Key words: hepatocellular carcinoma, RASSF1A hypermethylation, LINE-1 hypomethylation, prognosis

Hepatocellular carcinoma (HCC), the most common primary cancer of the live, is the sixth of most common malignant tumor type and the second leading cause of cancer-related mortality around the world [1]. For HCC patients, curative hepatic resection is the standard treatment, but their longterm prognosis remains poor [2]. Intrahepatic recurrences, especially within 2 year after surgical resection, are common and have been considered the main cause of poor prognosis in HCC patients. Inadequate resection, tumor invasiveness, tumor size, infiltration of the fibrous capsule, portal vein invasion and intrahepatic metastases have been reported as the main reasons for tumor recurrence [3]. But most of these factors can be detected only after tumor resection. Thus, it would be necessary to have a noninvasive, preoperative marker to identify patients who are at high risk of developing early recurrent tumors so that they may receive intensive therapy. 
Recent advance molecular biology studies suggest that genetic mutations and epigenetic alterations accumulated in repeated destruction and regeneration of hepatocytes are responsible for multistage hepatocarcinogenesis [4]. A widespread global DNA hypomethylation is accompanied by specific region hypermethylation including tumor suppressor genes' promoters in HCC [5]. Global loss of methylation in cancer may lead to chromosomal instability and alter expression of proto-oncogenes which is critical to carcinogenesis [6]. Hypermethylated status of CpG islands in the promoter region of the tumor suppressor genes which involve in cell cycle regulation, DNA repair, tumor metabolism, cell interactions, cell apoptosis and angiogenesis are able to cause their inappropriate silencing negatively affecting the initiation and progression of tumors [7]. Additionally, the technical advantage of DNA methylation is chemically stable and can be detected with a very high sensitivity up to 1:1000 molecular. And many cancer specific methylated DNA can be found in body fluids including serum which is the most easily treated sample [8]. Thus, detection of the methylation status of certain genes in serum DNA can be a useful noninvasive marker [9].

Long interspersed nucleotide element-1 retrotransposons - LINE-1 constitutes a substantial portion (about 17\%) of the human genome. And the level of LINE-1 methylation has be considered as a marker of global DNA methylation [10]. LINE-1 methylation status is highly variable, and LINE-1 hypomethylation can affect genomic instability, alter gene expression and closely associated with a poor prognosis in several types of human tumors, including colon, esophageal, gastric, and ovarian cancers $[11,12]$. Pattamadilok J showed that LINE-1 hypomethylation status in HCC tissue could be a biomarker for identifying poor prognosis [13]. Duo to LINE-1 hypomethylation could be detected in the white blood cells of cancer patients $[14,15]$. The methylation status of LINE-1 in serum DNA may not be a specifical biomarker alone for early recurrence of HCC patients. To enhance the specificity and accuracy, we combined with the hypermethylation status of a suppressor gene. The RAS association domain family $1 \mathrm{~A}$ gene - RASSF $1 A$, located in the

Table 1. Primer sequence used in MSP analyses.

\begin{tabular}{|c|c|c|c|}
\hline Gene & Direction & Sequence & bp \\
\hline \multicolumn{4}{|c|}{ Unmethylated } \\
\hline \multirow[t]{2}{*}{ RASSF1A } & Forward & 5'-GGGGTTTTGTGAGAGTGTGTTTAG-3’' & 175 \\
\hline & Reverse & 5'-TAAACACTAACAAACACAAACCAAAC-3' & \\
\hline \multirow[t]{2}{*}{ LINE1 } & Forward & 5'-TGTGTGTGAGTTGAAGTAGGGT-3' & 116 \\
\hline & Reverse & 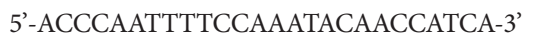 & \\
\hline \multicolumn{4}{|c|}{ Methylated } \\
\hline \multirow[t]{2}{*}{ RASSF1A } & Forward & 5'-GGGTTTTGCGAGAGCGCG-3' & 169 \\
\hline & Reverse & 5'-GCTAACAAACGCGAACCG-3' & \\
\hline \multirow[t]{2}{*}{ LINE1 } & Forward & 5'-CGCGAGTCGAAGTAGGGC-3' & 111 \\
\hline & Reverse & 5'ACCCGATTTTCCAAATACGACCG-3' & \\
\hline
\end{tabular}

3 p21.3 region, is a significant member of the RAS signaling pathway. It plays an important role in apoptosis, cell cycle, microtubule stability, cell adhesion and migration [16]. The promoter region hypermethylation of RASSF1A is suspected as a major silence mechanism in human malignant tumors, including HCC $[17,18]$. And a meta-analysis on RASSF1A methylation in HCC body fluids showed that RASSF1A hypermethylation could be a reliable biomarker for HCC discrimination and prognosis [19].

To determine whether combination of LINE-1 hypomethylation and RASSF1A promoter hypermethylation could be a noninvasive prognostic marker for postoperative HCC patients, we detected LINE-1 hypomethylation and RASSF1A promoter hypermethylation status in serum DNA, analyzed the association between genes methylation status and clinical pathologic features, and examined the correlation with disease free survival and overall survival after HCC patients underwent curative hepatic resection.

\section{Patients and methods}

Clinical samples. The study material consisted of 105 blood samples from HCC patients, and 75 among them underwent curative hepatic resection from West China Hospital, Sichuan University, between March and November in 2014. The diagnoses of HCC were verified by senior pathologist. None of the patients had received prior radiotherapy and chemotherapy treatment when the blood samples were collected. Complete pathological and clinical data were all collected and described in Table 2. All patients were informed consent. In addition, 50 blood samples were used as control group in NO.4 West China Teaching Hospital, Sichuan University. Besides, 1 normal liver tissue from healthy person who died of sudden accident was used as control to test the methylation status of LINE1 and RASSF1A.

Follow-up. Patients were followed up once a month after operation during the first half year, and then every 3 months afterwards. Serum AFP level and abdominal ultrasonography were performed each time during the routine review. Computed tomography (CT) was conducted every 3 to 6 months. Survival status of all patients was obtained from follow-up telephone calls by the endpoint of May 2016. The date of death for each patient was verified by local civil affairs department. Overall survival was calculated from the date of operation to the date of death or the last follow-up. Recurrence was confirmed on the basis of positron emission tomography-CT (PET-CT), or the combination of evidences from CT, ultrasonography, magnetic resonance imaging (MRI) and increased serum AFP levels, according to the latest guidelines released.

Cell line preparation. Cell line of Huh-7 which has been confirmed to contain $\mathrm{CpG}$ islands hypermethylation of RASSF1A promoter was chosen as positive hypermethylated control [20]. Cell line of K562 was chosen as hypomethylation control of LINE-1 [21]. 
Table 2. Association of RASSF1A methylation status with demographic and clinicopathological features of the patients

\begin{tabular}{|c|c|c|c|c|c|}
\hline Patient's characteristics & $\mathrm{n}$ & LINE1 hypomethylation & $p$ value & RASSF1A hypermethylation & $p$ value \\
\hline Gender & & & 0.349 & & 0.380 \\
\hline Females & 17 & $13(76.47)$ & & $11(64.7)$ & \\
\hline Males & 88 & $57(56.82)$ & & $66(75)$ & \\
\hline Age,years & & & 0.435 & & 0.218 \\
\hline$>45$ & 77 & $53(68.83)$ & & $54(70.13)$ & \\
\hline$\leq 45$ & 28 & $17(60.71)$ & & $23(82.14)$ & \\
\hline HBsAg & & & 0.009 & & 0.12 \\
\hline Positive+ & 97 & $68(70.1)$ & & $73(75.26)$ & \\
\hline Negative- & 8 & $2(25)$ & & $4(50)$ & \\
\hline Tumor size,cm & & & 0.001 & & 0.124 \\
\hline$\geq 5$ & 23 & $22(95.65)$ & & $14(60.87)$ & \\
\hline$<5$ & 26 & $14(53.85)$ & & $21(80.77)$ & \\
\hline AFP leve, ng/L & & & $<0.001$ & & 0.092 \\
\hline$>400$ & 45 & $39(86.67)$ & & $36(80)$ & \\
\hline$\leq 400$ & 60 & $31(51.67)$ & & $39(65)$ & \\
\hline Cirrhosis & & & 1 & & 0.372 \\
\hline With & 60 & $40(66.67)$ & & $46(76.7)$ & \\
\hline Without & 45 & $30(75)$ & & $31(68.89)$ & \\
\hline Porta vein tumor embolus & & & 0.851 & & 0.129 \\
\hline With & 17 & $11(64.7)$ & & $15(88.24)$ & \\
\hline Without & 88 & $59(67)$ & & $62(70.45)$ & \\
\hline Degree of cell differention & & & 0.280 & & 0.501 \\
\hline Moderately & 39 & $30(76.92)$ & & $27(69.23)$ & \\
\hline Poorly & 10 & $6(60)$ & & $8(80)$ & \\
\hline Lymph nodes metastasis & & & 0.442 & & 0.045 \\
\hline With & 16 & $12(75)$ & & $15(93.75)$ & \\
\hline Without & 89 & $58(65.17)$ & & $62(69.66)$ & \\
\hline
\end{tabular}

Statistically significant values are highlighted in bold

Huh-7 was cultured in DMEN (Gibco), while K562 was cultured in PRMI1640 (Gibco). Both media contained 10\% fetal bovine serum (BI), $100 \mathrm{IU} / \mathrm{ml}$ penicillin and streptomycin (Gibco). Well-grown passages were collected for genomic DNA extraction.

DNA extraction. According to the manufacture's instruction, DNA was extracted from tissues and cell lines with the TIANamp kit (TIANGEN) and dissolved in $150 \mu \mathrm{L}$ TE. Likewise, plasma DNA was isolated from $400 \mu \mathrm{L}$ sample using the Body Fluid Viral DNA/RNA Miniprep Kit (Axygen) and then dissolved in $40 \mu \mathrm{L}$ TE.

Bisulfite conversion of DNA and MSP. In order to convert all unmethylated-cytosines to uracil, extracted DNA was modified, using sodium bisulfite (SB) from the EZ DNA Methylation (ZYMO Research Co.). Based on the manufacturer's instructions, extracted DNA was added to each conversion system up to $500 \mathrm{ng}$. then modified DNA was stored at $-80^{\circ} \mathrm{C}$ until used.

The methylated status of LINE-1 and RASSF1A in serum DNA samples was tested by Methylation Specific PCR (MSP) using specific primer pairs for the methylated and unmethylated sequences. The primer sequences and length of products are shown in Table 1. According to the manufacture's instruction, two $\mu \mathrm{L}$ of sodium bisulfite modified DNA was added into a $23 \mu \mathrm{L}$ reaction mixture that contained $12.5 \mu \mathrm{L} 2 \mathrm{xTaq}$ Master Mix (Novoprotein Scientific Inc.) and $1.5 \mu \mathrm{L}$ of corresponding forward and reverse primers $(10 \mu \mathrm{mol} / \mathrm{L})$; then $\mathrm{dH}_{2} \mathrm{O}$ was added to a final volume of $25 \mu \mathrm{L}$. And sodium bisulfite treated DNA was amplified with PCR instrument. Thermo-cycling condition was used as follows: (i) LINE-1, one cycle at $95^{\circ} \mathrm{C}$ for $5 \mathrm{~min}$, followed by 30 cycles of $95^{\circ} \mathrm{C}$ for $45 \mathrm{~s}, 58^{\circ} \mathrm{C}$ for $45 \mathrm{~s}$ and $72^{\circ} \mathrm{C}$ for $30 \mathrm{~s}$, with a final extension cycle of $72^{\circ} \mathrm{C}$ for $10 \mathrm{~min}$ [22]. (ii) RASSF1A, one cycle at $95^{\circ} \mathrm{C}$ for $5 \mathrm{~min}$, followed by 30 cycles of $95^{\circ} \mathrm{C}$ for $45 \mathrm{~s}$, $63^{\circ} \mathrm{C}$ for $30 \mathrm{~s}$ and $72^{\circ} \mathrm{C}$ for $30 \mathrm{~s}$, with a final extension cycle of $72^{\circ} \mathrm{C}$ for $10 \mathrm{~min}$ [23].

MSP products were fractionated on $2 \%$ agarose gels, stained with ethidium bromide, and visualized under UV illumination. Our criterion for methylation status of LINE-1 was follow: samples with band in both the methylation and unmethylation specific reaction were regarded as hypomethylated. For RASSF1A, samples only with band in the methylation or unmethylation specific reaction were considered as hypermethylated or unmethylated, respectively. 
A

Methylated LINE1

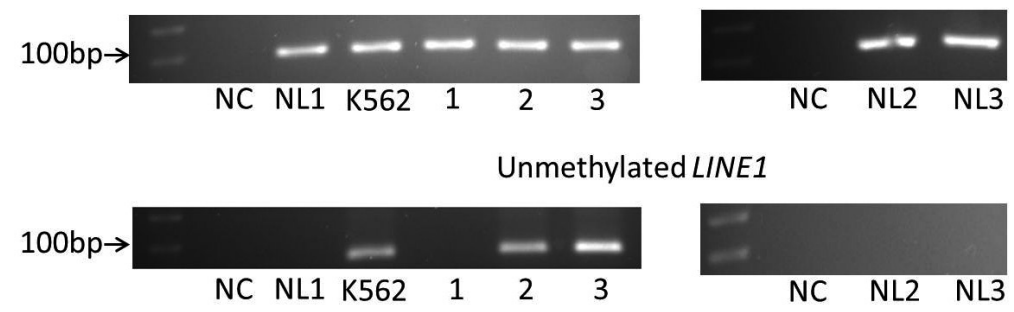

B

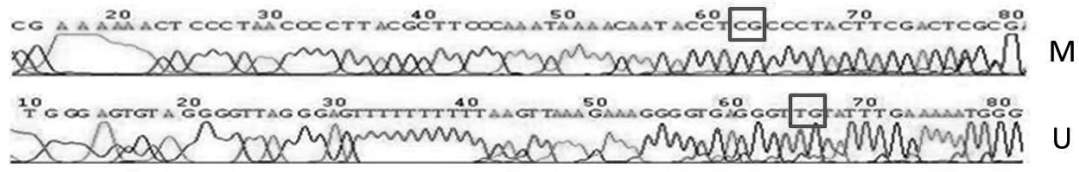

C
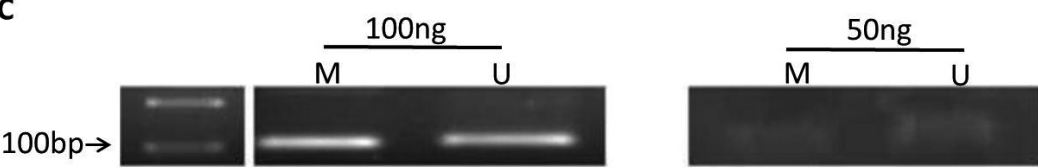

Figure 1. Methylation analysis of LINE-1 by methylation specific PCR in serum DNA from HCC. (A) methylated LINE-1(NC= negative control, no DNA. NL=normal liver tissue DNA, 100\% methylated. 1-3=patient's samples) and unmethylated LINE-1 (NC= negative control, no DNA. cell line DNA of K562 used as hypomethylated control. 1-3=patient's samples). (B) The specificity was proved by the sequence of MSP product (M= the methylated LINE-1, $\mathrm{U}=$ the unmethylated LINE-1, black Frame represented the methylated CpG site).The sequences were consistent with the purpose fragments and CpG island in methylated was replaced by TpG in unmethylated fragment. (C) The sensitivity was detected using normal palsma DNA added K562 DNA with 100ng-50ng. And LINE-1 unmethylation status could be tested with strong signals, when K562 DNA concentration reached or exceeded 100ng. Or weak signals could be detected if the reaction system contained DNA greater than or equal to 50ng.

A

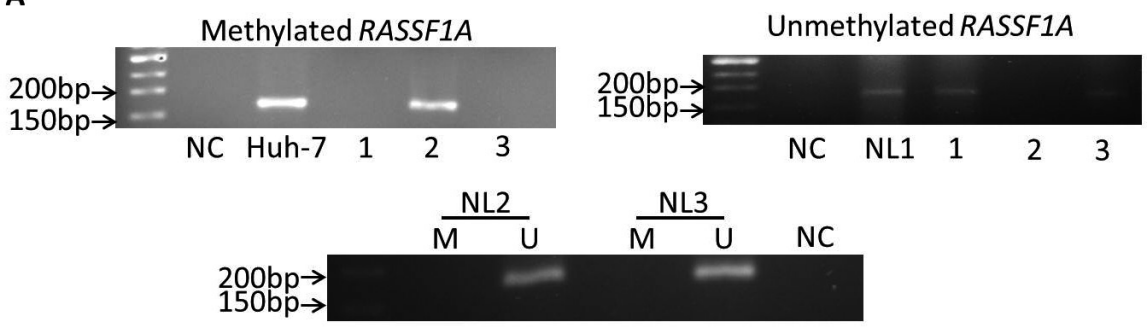

B

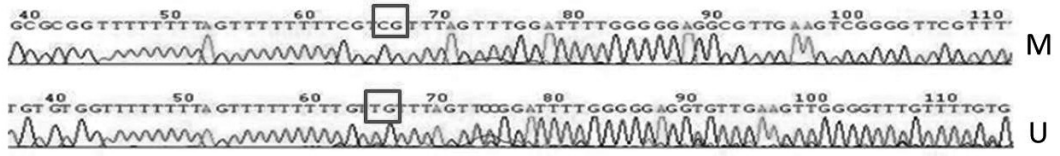

C
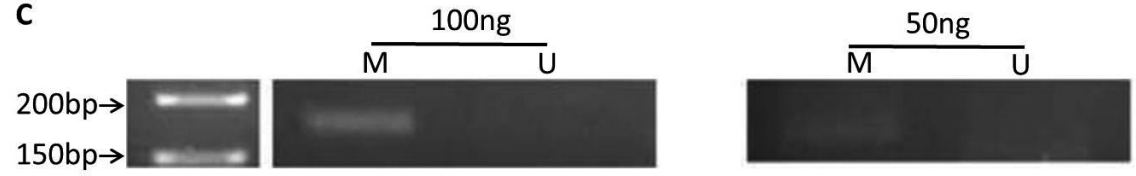

Figure 2. Methylation analysis of RASSF1A by methylation specific PCR in serum DNA from HCC. (A) methylated RASSF1A (NC= negative control, no DNA. Cell line DNA of Huh-7 used as positive control, $100 \%$ hypermethylated. 1-3=patient's samples) and unmethylated RASSF1A (NC= negative control, no DNA. NL=normal liver tissue DNA, totally unmethylated. 1-3=patient's samples). (B) The specificity was proved by the sequence of MSP product ( $\mathrm{M}=$ the methylated RASSF1A, $\mathrm{U}=$ the unmethylated RASSF1A, Black Frame represented the methylated CpG site). The sequences were consistent with purpose fragments and CpG island in methylated was replaced by TpG in unmethylated fragment. (C) The sensitivity was detected using normal palsma DNA added Huh-7 DNA with 100ng-50ng. And RASSF1A methylation status could be tested with strong signals, when Huh-7 DNA concentration reached or exceeded 100ng. Or weak signals could be detected if the reaction system contained DNA greater than or equal to 50ng. 
After electrophoresis detection, the methylated and unmethylated products of MSP in HCC samples were randomly collected with DNA Purification Kit (TIANGEN) and sequenced (Sangon Biotech). The methylated and unmethylated fragments of LINE-1 and RASSF1A were compared with DNAMAN, separately.

To test the sensitivity of MSP system, K562 and Huh-7 cell lines was chose as positive controls for unmethylated LINE-1 and methylated RASSF1A, separately. And DNA from cell lines (50ng-100ng) was respectively added in $400 \mu \mathrm{L}$ normal plasma. Then, plasma DNA isolated, bisulfite conversion and MSP were performed.

Statistical analysises. The data was analysed by using the Social Sciences (SPSS), version 20.0 (IBM). The methylation status of LINE-1 and RASSF1A and all other qualitative variables were represented as frequencies and percentages (\%). The chi-square test was used to assess any potential association of LINE-1 and RASSF1A methylation status with patient's demographic and clinical pathological characteristics. Survival rates were calculated by using Kaplan-Meier method with log-rank test and Breslow test. Multivariate Cox proportional hazards regression analysis was applied to investigate the independent effect of LINE-1 and RASSF1A methylation status on survival. Patient's gender, age, tumor size, AFP level and HBsAg condition were also involved in the multivariate model as potential confounding factors. All tests were two tailed and $\mathrm{p}$ values $<0.05$ was considered as statistical significance.

\section{Results}

The methylation status of LINE-1 and RASSF1A was evaluated in serum DNA samples from 105 patients diagnosed with HCC in double-blinded experiments. Patient's clinical pathological characteristics (Table 2) and clinical data become available after tumor resection for the statistical correlations. LINE-1 hypomethylated in $70(66.7 \%)$ and RASSF1A promoter hypermethylated in $77(73.3 \%)$. But none of them was found in control sample.

\section{A}

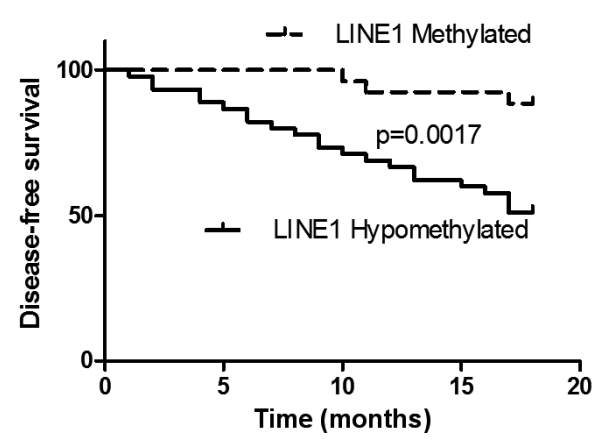

Association between LINE-1 hypomethylation and RASSF1A promoter hypermethylation status and tumor parameters in serum DNA with HCC patients. Chisquare analysis showed a significant association between hypomethylated LINE-1 status and HBsAg positive condition $(70.1 \%$ vs $25 \%, \mathrm{p}=0.009)$, bigger tumor size $(95.65 \%$ vs $53.85 \%, \mathrm{p}=0.001)$ as well as high AFP levels $(86.67 \%$ vs $51.67 \%, \mathrm{p}<0.001)$. And only a significant relation between hypermethylated RASSF1A promoter status with lymph nodes metastasis $(93.75 \%$ vs $69.66 \%, \mathrm{p}=0.045)$ was detected. No other significant associations between LINE-1 hypomethylation and RASSF1A promoter hypermethylation status and other tumor parameters detected were found. The associations of demographic and clinical pathological characteristics with LINE-1 hypomethylation and RASSF $1 A$ promoter hypermethylation status are given in Table 2. Coexpression of hypomethylated LINE-1 and hypermethylated RASSF1A promoter were found $54(51.43 \%)$ of HCC samples and its presence was associated with high AFP levels (82.22\% vs $28.33 \%, \mathrm{p}=0.02)$ and lymph nodes metastasis $(81.25 \%$ vs $46.07 \%, \mathrm{p}=0.01$ ).

Association between LINE-1 hypomethylation and RASSF $1 A$ promoter hypermethylation status and survival in serum DNA with HCC patients. Following up 75 cases of HCC patients underwent curative hepatic resection for 18 months, 14 (19.72\%) patients have died due to a consequence of disease progression. LINE-1 hypomethylation and RASSF1A hypermethylation was detected in $13(92.86 \%)$ and $10(71.43 \%)$ of these patients, respectively. The incidence of death was significantly higher in patients with hypomethylated LINE-1 than methylated LINE-1 (28.9\% vs $3.8 \%$, $\mathrm{p}=0.015$ ), but it was independent of the RASSF1A promoter hypermethylation status (14.28\% in unmethylated vs $20 \%$ in hypermethylated, $\mathrm{p}=0.766$ ).

The Kaplan-Meier estimates of survival rates, significantly benefited patients with a methylated LINE- 1 status (Fig. 3A disease-free survival rates, Log Rank test: $\mathrm{p}=0.0017$, Breslow test: $p=0.0015$; Fig. 3 B overall survival rate, Log Rank

B

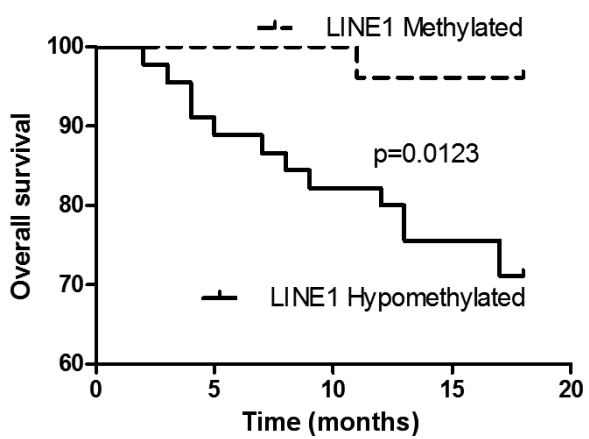

Figure 3. Kaplan Meier estimate of disease-free survival (A) and overall survival (B) for HCC with LINE-1 methylation or hypomethylation. Survival time was defined as the time from curative resection to death or last time know follow up. The difference between groups was tested by log rank test. 
A

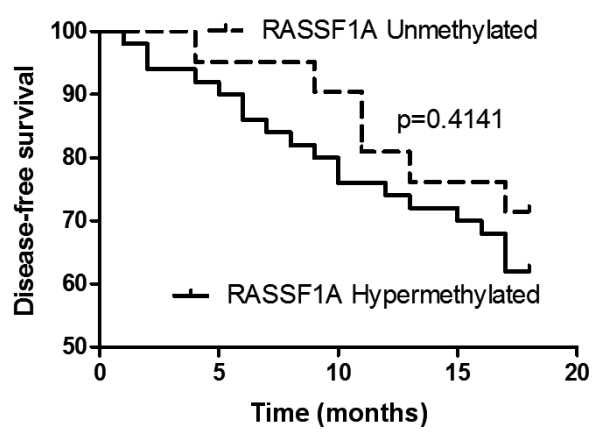

B

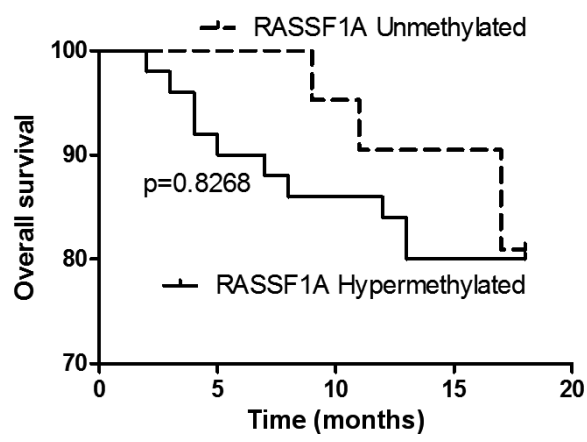

Figure 4. Kaplan Meier estimate of disease-free survival (A) and overall survival (B) for HCC with RASSF1A promoter hypermethylation or unmethylation. Survival time was defined as the time from curative resection to death or last time know follow up. The difference between groups was tested by log rank test.
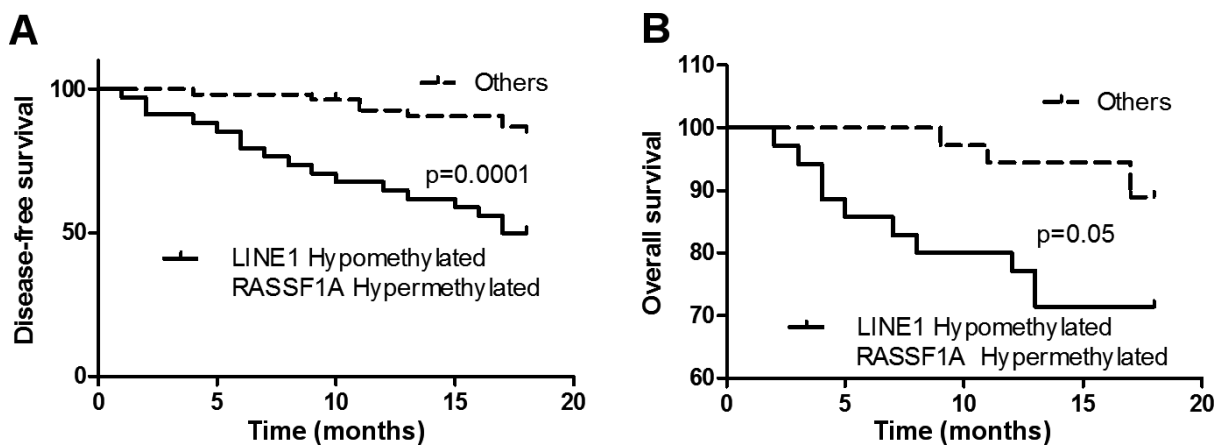

Figure 5. Kaplan Meier estimate of disease-free survival (A) and overall survival (B) for HCC categorized according to co-expression of LINE-1 hypomethylation and RASSF1A promoter hypermethylation. The difference between groups was tested by log rank test.

test: $\mathrm{p}=0.0123$, Breslow test: $\mathrm{p}=0.0122$ ). Patients' survival was not significantly correlated with $R A S S F 1 A$ promoter hypermethylation status (Fig. 4A disease-free survival rates, Log Rank test: $p=0.41$, Breslow test: $p=0.38$; Fig. $4 B$ overall survival rate, Log Rank test: $\mathrm{p}=0.827$, Breslow test: $\mathrm{p}=0.734$ ). The association of overall survival with the co-expression of hypomethylated $L I N E-1$ and hypermethylated RASSF1A promoters was marginal statistical significance (Fig. 5B Log Rank test: $\mathrm{p}=0.05$, Breslow test: $\mathrm{p}=0.0393$ ). Remarkably, the correlation with disease-free survival was statistical significance (Fig. 5A Log Rank test: $\mathrm{p}=0.0001$, Breslow test: $\mathrm{p}<0.0001)$.

Further investigation with multivariate Cox proportional hazards regression analysis revealed that only hypomethylated LINE- 1 status $(\mathrm{p}=0.045)$ remained the main statistically significant independent determinants for poor overall survival. Other parameters, such as gender $(\mathrm{p}=0.543)$, age $(\mathrm{p}=0.545)$, HBsAg status (0.564), tumor size ( $\mathrm{p}=0.289)$, AFP level (0.987), cirrhosis $(0.661)$, lymph nodes metastasis $(\mathrm{p}=0.153)$ and RASSF1A hypermethylated status ( $\mathrm{p}=0.685)$ were not significantly associated with overall survival.

\section{Discussion}

Epigenetic alterations play important role in human carcinogenesis, which contribute to the initiation of cancer and also trigger genetic events leading to tumor development [24]. To date, DNA methylation is the most commonly studied epigenetic mechanism, and is involved in the tumorigenesis of nearly all cancer types, including HCC [25]. Widespread global DNA hypomethylation accompanied by specific region hypermethylation including tumor suppressor genes is a common feature found in HCC [9]. It is one of the major molecular alterations in the process of HCC carcinogenesis and also a potential diagnostic and prognostic bio-marker [26].

In this study, as a marker of global DNA methylation, LINE-1 hypomethylation was detected in 70 (66.7\%) out of the 105 examined cases, which indicated an important role in HCC. A significant correlation between LINE-1 hypomethylation status and HBsAg positive, bigger tumor size was also observed. The result is in keeping with the study reported by Pisit Tangkijvanich [27]. In addition, significant correlation between LINE-1 hypomethylation status and 
high AFP levels was found. This finding is in accordance with Iman I. Ramzy [28]. In general, LINE-1 hypomethylation was possibly an efficacy epigenetic biomarker in $\mathrm{HBV}$ induced and high AFP level patients alone, but not for all HCC patients.

Regarding RASSF1A promoter, it was found to be hypermethylated in 77 (73.3\%) from our cases, which is a relative high methylation frequency. And it may be indicative of its crucial role in HCC carcinogenesis. Besides, the protein encoded by RASSF1A which was reported to share a similar conformation with RAS effector proteins is thus highly possible to act as a tumor suppressor in normal hepatocytes to prohibit the development and progress of HCC. Additionally, we detected that hypermethylation of RASSF1A was only significantly correlated with metastasis of regional lymph nodes $(\mathrm{p}=0.045)$. And there was no significant relation with $\mathrm{HBsAg}$ positive $(\mathrm{p}=0.12)$ and high AFP level $(\mathrm{p}=0.092)$.

patient's disease-free survival and overall survival were analyzed with combination of LINE-1 hypomethylated and RASSF1A promoter hypermethylated status or respectively. There is no significant relation with the RASSF1A promoter hypermethylation and prognosis. Thus, RASSF1A promoter hypermethylation may not be a useful biomarker alone for HCC agreeing with Xu B [29]. Interestingly, A more significant correlation was detected in disease-free survival rate (Log Rank test, $\mathrm{p}<0.001$; Breslowtest, $\mathrm{p}<0.001$ ) than LINE-1 hypomethylation alone (Log Rank test: $\mathrm{p}=0.0017$, Breslow test: $\mathrm{p}=0.0015)$. HCC patients co-expressing LINE-1 hypomethylation and RASSF1A promoter hypermethylation have short disease free time and more easily relapse after curative hepatic resection. The mechanism is not very clear. Maybe HCC both with LINE-1 hypomethylation and RASSF1A promoter hypermethylation possessed more potential deteriorative and aggressive ability. Besides, due to inadequate observed time, there is only marginal significant correlation was detected in overall survival rate (Log Rank test, $\mathrm{p}=0.05$; Breslow test, $\mathrm{p}=0.0393$ ). In additional study, a longer follow-up time need to be further explored.

In conclusion, we found that LINE- 1 hypomethylation and RASSF1A promoter hypermethylation are frequent epigenetic event in HCC patients. We also observed a significant correlation between LINE-1 hypomethylated status and survival as well as between a hypermethylated RASSF1A promoter and lymph nodes metastasis. Notably, patients with co-expression of LINE-1 hypomethylation and RASSF1A promoter hypermethylation status have shorter disease free time and more easily recur after tumor resection. Therefore, HCC patients with both hypomethylated LINE-1 and hypermethylated RASSF1A promoter in serum DNA should require more intensive therapy and need to be closely observed after curative resection.

Acknowledgments: This study was supported by Science \& Technology Department of Sichuan Province [no. 2013SZ0048]

\section{References}

[1] TORRE LA, BRAY F, SIEGEL RL, FERLAY J, LORTETTIEULENT J et al. Global cancer statistics, 2012. CA Cancer J Clin 2015; 65: 87-108. https://doi.org/10.3322/caac.21262

[2] OKUDA K, OHTSUKI T, OBATA H, TOMIMATSU M, OKAZAKI $\mathrm{N}$ et al. Natural history of hepatocellular carcinoma and prognosis in relation to treatment. Study of 850 patients. Cancer 1985; 56: 918-928. https://doi.org/10.1002/10970142(19850815)56:4<918::AID-CNCR2820560437>3.0.CO;2E

[3] SHIRABE K, KANEMATSU T, MATSUMATA T, ADACHI E, AKAZAWA K et al. Factors linked to early recurrence of small hepatocellular carcinoma after hepatectomy: univariate and multivariate analyses. Hepatology 1991; 14: 802-805. https:// doi.org/10.1002/hep. 1840140510

[4] ROBERTS LR, GORES GJ. Hepatocellular carcinoma: molecular pathways and new therapeutic targets. Semin Liver Dis 2005; 25: 212-225. https://doi.org/10.1055/s-2005-871200

[5] FEINBERG AP, TYCKO B. The history of cancer epigenetics. Nat Rev Cancer 2004; 4: 143-153. https://doi.org/10.1038/ $\underline{\operatorname{nrc1279}}$

[6] GAUDET F, HODGSON JG, EDEN A, JACKSON-GRUSBY $\mathrm{L}$, DAUSMAN J et al. Induction of tumors in mice by genomic hypomethylation. Science 2003; 300: 489-492. https://doi. org/10.1126/science. 1083558

[7] BAYLIN SB. DNA methylation and gene silencing in cancer. Nat Clin Pract Oncol 2005; 2 Suppl 1: S4-11. https://doi. org/10.1038/ncponc0354

[8] JUNG K, FLEISCHHACKER M, RABIEN A. Cell-free DNA in the blood as a solid tumor biomarker--a critical appraisal of the literature. Clin Chim Acta 2010; 411: 1611-1624. https:// doi.org/10.1016/j.cca.2010.07.032

[9] NAKAJIMA T, ENOMOTO S, USHIJIMA T. DNA methylation: a marker for carcinogen exposure and cancer risk. Environ Health Prev Med 2008; 13: 8-15. https://doi. org/10.1007/s12199-007-0005-X

[10] CORDAUX R, BATZER MA. The impact of retrotransposons on human genome evolution. Nat Rev Genet 2009; 10: 691-703. https://doi.org/10.1038/nrg2640

[11] IWAGAMI S, BABA Y, WATANABE M, SHIGAKI H, MIYAKE $\mathrm{K}$ et al. LINE-1 hypomethylation is associated with a poor prognosis among patients with curatively resected esophageal squamous cell carcinoma. Ann Surg 2013; 257: 449-455. https://doi.org/10.1097/SLA.0b013e31826d8602

[12] SHIGAKI H, BABA Y, WATANABE M, MURATA A, IWAGAMI S et al. LINE-1 hypomethylation in gastric cancer, detected by bisulfite pyrosequencing, is associated with poor prognosis. Gastric Cancer 2013; 16: 480-487. https://doi.org/10.1007/ $\underline{\text { s10120-012-0209-7 }}$

[13] HARADA K, BABA Y, ISHIMOTO T, CHIKAMOTO A, KOSUMI K et al. LINE-1 methylation level and patient prognosis in a database of 208 hepatocellular carcinomas. Ann Surg Oncol 2015; 22: 1280-1287. https://doi.org/10.1245/s10434014-4134-3

[14] HSIUNG DT, MARSIT CJ, HOUSEMAN EA, EDDY K, FURNISS CS et al. Global DNA methylation level in whole blood 
as a biomarker in head and neck squamous cell carcinoma. Cancer Epidemiol Biomarkers Prev 2007; 16: 108-114. https:// doi.org/10.1158/1055-9965.EPI-06-0636

[15] WILHELM CS, KELSEY KT, BUTLER R, PLAZA S, GAGNE L et al. Implications of LINE1 methylation for bladder cancer risk in women. Clin Cancer Res 2010; 16: 1682-1689. https:// doi.org/10.1158/1078-0432.CCR-09-2983

[16] AGATHANGGELOU A, HONORIO S, MACARTNEY DP, MARTINEZ A, DALLOL A et al. Methylation associated inactivation of RASSF1A from region 3p21.3 in lung, breast and ovarian tumours. Oncogene 2001; 20: 1509-1518. https:// doi.org/10.1038/sj.onc. 1204175

[17] DONNINGER H, VOS MD, CLARK GJ. The RASSF1A tumor suppressor. J Cell Sci 2007; 120: 3163-3172. https://doi. org/10.1242/jcs.010389

[18] VAN DER WEYDEN L, ADAMS DJ. The Ras-association domain family (RASSF) members and their role in human tumourigenesis. Biochim Biophys Acta 2007; 1776: 58-85. https://doi.org/10.1016/j.bbcan.2007.06.003

[19] ZHAO ZH, FAN YC, YANG Y, WANG K. Association between Ras association domain family $1 \mathrm{~A}$ promoter methylation and hepatocellular carcinoma: a meta-analysis. World J Gastroenterol 2013; 19: 7189-7196. https://doi.org/10.3748/wjg.v19. i41.7189

[20] ZHONG S, YEO W, TANG MW, WONG N, LAI PB et al. Intensive hypermethylation of the $\mathrm{CpG}$ island of Ras association domain family $1 \mathrm{~A}$ in hepatitis $\mathrm{B}$ virus-associated hepatocellular carcinomas. Clin Cancer Res 2003; 9: 3376-3382.

[21] ESTECIO MR, GHARIBYAN V, SHEN L, IBRAHIM AE, DOSHI K et al. LINE-1 hypomethylation in cancer is highly variable and inversely correlated with microsatellite instability. PLoS One 2007; 2: e399. https://doi.org/10.1371/journal. pone.0000399

[22] WANG G, GAO J, HUANG H, TIAN Y, XUE L et al. Expression of a LINE-1 endonuclease variant in gastric cancer: its association with clinicopathological parameters. BMC Cancer 2013; 13: 265. https://doi.org/10.1186/1471-2407$\underline{13-265}$

[23] HONDA S, HARUTA M, SUGAWARA W, SASAKI F, OHIRA $\mathrm{M}$ et al. The methylation status of RASSF1A promoter predicts responsiveness to chemotherapy and eventual cure in hepatoblastoma patients. Int J Cancer 2008; 123: 1117-1125. https://doi.org/10.1002/ijc.23613

[24] PORTELA A, ESTELLER M. Epigenetic modifications and human disease. Nat Biotechnol 2010; 28: 1057-1068. https:// doi.org/10.1038/nbt.1685

[25] Jaenisch R, Bird A. Epigenetic regulation of gene expression: how the genome integrates intrinsic and environmental signals. Nat Genet 2003; 33 Suppl: 245-254. https://doi. org/10.1038/ng1089

[26] NISHIDA N, NAGASAKA T, NISHIMURA T, IKAI I, BOLAND CR et al. Aberrant methylation of multiple tumor suppressor genes in aging liver, chronic hepatitis, and hepatocellular carcinoma. Hepatology 2008; 47: 908-918. https:// doi.org/10.1002/hep.22110

[27] TANGKIJVANICH P, HOURPAI N, RATTANATANYONG P, WISEDOPAS N, MAHACHAI V et al. Serum LINE-1 hypomethylation as a potential prognostic marker for hepatocellular carcinoma. Clin Chim Acta 2007; 379: 127-133. https://doi.org/10.1016/j.cca.2006.12.029

[28] RAMZY II, OMRAN DA, HAMAD O, SHAKER O, ABBOUD A. Evaluation of serum LINE-1 hypomethylation as a prognostic marker for hepatocellular carcinoma. Arab J Gastroenterol 2011; 12: 139-142. https://doi.org/10.1016/j. ajg.2011.07.002

[29] XU B, DI J, WANG Z, HAN X, LI Z et al. Quantitative analysis of RASSF1A promoter methylation in hepatocellular carcinoma and its prognostic implications. Biochem Biophys Res Commun 2013; 438: 324-328. https://doi.org/10.1016/j. bbrc.2013.07.070 